\title{
Implication of Serum Zinc level with duration and clinical type of Vitiligo.
}

\author{
Sohail Mirza ${ }^{1}$, Mohammad. Eakub Ali ${ }^{2}$, Lubna Khondker ${ }^{3}$, Md Shirajul Islam Khan ${ }^{4}$, Nadia Islam ${ }^{1}$, Muhammad \\ Munir Rashid ${ }^{2}$.
}

\begin{abstract}
${ }^{1}$ Student, Bangabandhu Sheikh Mujib Medical University (BSMMU), Dhaka. ${ }^{2}$ Associate Professor, Department of Dermatology and Venereology, BSMMU. ${ }^{3}$ Assistant Professor, Dept of Dermatology and Venereology, BSMMU. ${ }^{4}$ Graded Specialist in Dermatology and Venereology, CMH, Dhaka, Bangladesh.
\end{abstract}

\begin{abstract}
:
Background: Vitiligo is a common dermatological disorder characterized by acquired, idiopathic, progressive, hypomelanosis of the skin and hair, with total absence of melanocytes microscopically. Objective: The study was conducted to find out the relationship between serum zinc level and clinical spectrum of vitiligo. Methods: A cross sectional study conducted in the department of Dermatology and Venereology and department of Biochemistry, Bangabandhu Sheikh Mujib Medical University (BSMMU), Dhaka, Bangladesh and the period of study was from May 2010 to October 2011. Results: The mean difference of serum zinc level in male and female of both groups were significant $(p<0.05)$ but the mean serum zinc level was not significantly different $(p>0.05)$ among various clinical types of vitiligo. In case of localized vitiligo mean serum zinc level was $755.3 \pm 288.6$, in case of acrofacial vitiligo mean serum zinc level was $821.4 \pm 259.6$ and in case of generalized vitiligo mean serum zinc level was $771.6 \pm 222.2$. The difference of mean serum zinc level observed between family history positive and negative group were not statistically significant ( $\mathrm{p}>0.05$ ). The difference of mean serum zinc level was also not statistically significant $(\mathrm{p}>0.05)$ among $<1$ year, $1-10$ years and 11-20 years duration groups of vitiligo patients. A negative correlation $(r=-0.227)$ was observed between duration of symptom with serum zinc level in this study. Conclusion: This study showed low level of serum zinc in vitiligo patients. Large-scale studies are needed to confirm these findings and multicenter study should be carried out to reveal the accurate pattern of zinc status in vitiligo.
\end{abstract}

Key words: Serum zinc in vitiligo, association of zinc with vitiligo, vitiligo

[BSMMU J 2013; 6 (2) : 99-103]

\section{Introduction:}

Vitiligo is an acquired, often disfiguring, pigmentary anomaly of the skin manifested by depigmented white patches surrounded by a normal or a hyperpigmented border.1 Vitiligo usually begins in childhood or adulthood with about half of the cases begin before age 20 . The prevalence of the disease ranges from $0.5 \%$ to $1 \% .2,3$ The aetiology of the disease is still unknown. Traditionally, there have been three hypothesis to explain vitiligo: neural, immune and self-destruct hypothesis. ${ }^{4}$ Despite the fact that the aetiology and pathogenesis of vitiligo is not completely known yet, many factors may be responsible for the disease. Many possible causes, including stress,

Address for Correspondence: Dr. Sohail Mirza, Student of MD (Dermatology) BSMMU, Dhaka. accumulation of toxic compounds, infections, autoimmunity, mutations, melatonin receptor dysfunction, altered cellular environment and impaired melanocyte migration or proliferation can lead to the acquired hypopigmentation that characterizes vitiligo. ${ }^{5}$ Vitiligo is a very common disease in dermatological practice. The cosmetic disfigurement has a substantial impact on a person's social and professional relationships. Vitiligo may cause serious psychosocial problems for those afflicted. ${ }^{6}$ The prognosis and course of vitiligo are unpredictable.

Zinc is considered as an antioxidant because the extracellular enzyme superoxide dismutase is zinc-dependent. ${ }^{8}$ It plays a vital role in the protection against free radical damage. Zinc as a trace element, plays an important role in the process of melanogenesis. Trace elements including zinc catalyze the rearrangement of dopachrome to form 5 , 
zinc catalyze the rearrangement of dopachrome to form 5 , 6-dihydroxy indole-2 carboxylic acid (DICA) in the process of melanogenesis. ${ }^{9}$ There are different treatment options but none is appropriate for every patient with vitiligo. So, investigations are attempted worldwide for more suitable solutions. In some studies variable degree of correlation between serum zinc level and vitiligo were observed. Serum zinc level was found significantly low in vitiligo patients than normal populations in some studies. ${ }^{10,11,12}$ These previous studies recommended for further studies to be carried out revealing pattern of zinc status in vitiligo. Variable informations from above studies have provided a rationale to conduct the current study. The present study was conducted to measure the serum zinc level across clinical spectrum of vitiligo and to compare it with age and sex-matched controls. The study result will provide benefit to the society by providing information regarding vitiligo patients in our country.

\section{Methods:}

A cross sectional study conducted in the department Dermatology and Venereology; in collaboration with department of Biochemistry, Bangabandhu Sheikh Mujib Medical University (BSMMU), Dhaka, Bangladesh. The period of study was from May 2010 to October 2011 and purposive type of non probability sampling technique was followed in this study. A data collection sheet was used for submission of data. Sixty patients with vitiligo attending out-patient department of Dermatology and Vereneology as case and 50 age and sex matched individual without vitiligo as control were enrolled. Cases were grouped into Group A and controls were grouped into Group B.

Inclusion criteria's for cases were patients of any age and both sexes, patients not on any treatment with zinc or drugs affecting zinc level in the four weeks prior to diagnosis and patient who gave informed consent to be included in the study. Inclusion criterias for control were age and sex matched individual without vitiligo and without the family history of vitiligo, individuals who were willing to give consent to be included in the study and patients not on any form of zinc medication or drugs affecting zinc level. Exclusion criterias were patient with leukoderma secondary to other causes and other skin diseases (eg; exfoliative dermatitis, extensive skin burn), patient on any treatment with Zinc or drugs affecting zinc level, patient with other systemic diseases such as liver disease, neoplastic condition, intestinal disease, psychological disease and renal disease, patients having history of alcohol intake, pregnancy and patients with gastrointestinal surgery intercurrent illness or other stressful conditions or on prolong parenteral nutrition.

All patients were explained about the potential risks and obtainable benefits of the study and they were included in the trial after taking their informed consent. The researcher explained them that they have the right to refuse or accept to participate in the study. All patients were ensured that all data obtained during study period from them will be remained confidential. Controls were also included in the trial after taking their informed consent.

This cross sectional study was conducted in the department of Dermatology and venereology, BSMMU, Dhaka. Total sixty vitiligo patients were taken as case and 50 age and sex matched individuals without vitiligo from a selected community were taken as control. They were approached for the study. The aims and objectives of the study along with its procedure, risks and benefits were explained to the patients in easily understandable local language and then informed written consent were taken from the interested patients and controls. Sociodemographic data were taken from the patients or reliable informants. Vitiligo patients were selected clinically from patients with whitish depigmented patches excluding patients with leukoderma secondary to other causes such as pityriasis alba, sarcoidosis, scleroderma, pityriasis versicolor, post inflammatory hypomelanosis etc. The diagnosis was confirmed by Wood's lamp examination for study purpose and all other selection criteria's also were fulfilled for each case and control. Then $5 \mathrm{ml}$ of venous blood was collected in special a sterile tube from both cases and control and was centrifuged for 15 minutes at $2000 \mathrm{rpm}$ (Rotations per minute). The supernatant serum was transferred to a separate sterile tube (Appendorf) and kept at $-35^{\circ} \mathrm{C}$ in the deep freezer till the analysis. The serum zinc levels were measured by Atomic absorption spectrophotometer (AAS) [Grapphyte Method] at 
Biochemistry Dept. of BSMMU. Then serum zinc level of the vitiligo patients were compared with both age and sex matched controls and internationally accepted normal serum zinc level (700-1200 ppb).

After collection, data were checked for inadequacy, irrelevancy, and inconsistency. Irrelevant and inconsistent data were discarded. Analysis of data was performed by chi square test and unpaired $t$ test and ANOVA TEST by using SPSS (The Statistical Package for the Social Science for the Windows 16.0) software. Statistical significance has been set at $5 \%$ level and confidence interval at $95 \%$ level.

\section{Results:}

This case control study conducted in the department of Dermatology and Venereology of Bangabanddhu Sheikh Mujib Medical University, Dhaka. Cases were grouped into Group A and controls were grouped into Group B. The main objective of the study was to find out the relationship between serum zinc level with vitiligo. Mean age of the group A patients was 29.9 years with a standard deviation of \pm 13.9 years and in group B 31.5 years with a standard deviation of \pm 9.0 years. The mean difference was not significant $(p>0.05)$ between these two groups. Male was found $27(45.0 \%)$ in group A and $28(56.0 \%)$ in group B. Female was found $33(55.0 \%)$ and $22(44.0 \%)$ in group A and group $B$ respectively. The difference was not statistically significant $(p>0.05)$ between these two groups. The mean serum zinc levels observed in male were $768.5 \pm 233.8 \mathrm{ppb}$ and $939.3 \pm 218.7 \mathrm{ppb}$ in group A and group $\mathrm{B}$ respectively. In female the mean serum zinc level were $719.7 \pm 258.9 \mathrm{ppb}$ in group $A$ and $975 \pm 334.1 \mathrm{ppb}$ in group B. The mean difference of serum zinc level in male and female of both groups were significant $(\mathrm{p}<0.05)$. There was no significant difference of mean serum zinc level between male and female in each group (Table I). Serum zinc level was significantly lower in group-A (case) than that of group-B (control). But, serum zinc level was normal and higher respectively in group B (control) than that of group-A (case) which were statistically significant (Table II).

The mean serum zinc level was not significantly different
( $>0.05$ ) among various clinical types of vitiligo. In case of localized vitiligo mean serum zinc level was $755.3 \pm$ 288.6, in case of acrofacial vitilig, mean serum zinc level was $821.4 \pm 259.6$ and in case of generalized vitiligo mean serum zinc level was $771.6 \pm 222.2$.(Table III). The difference of mean serum zinc level observed between family history positive group and in family history negative group was not statistically significant $(p>0.05)$ between these two groups. The mean serum zinc level of family history positive group was $756.9 \pm 242.7$ and the mean serum zinc level of family history negative group was 662 (Table IV). The difference of mean serum zinc level was not statistically significant ( $p>0.05$ ) among $<1$ year, 1-10 years and 11-20 years duration groups of vitiligo patients. The mean serum zinc level among the duration $<1$ year was $734.6 \pm 243.6$, the mean serum zinc level among the duration $1-10$ years was $723.6 \pm 238$ and the mean serum zinc level among the duration 11-20 years was $780.0 \pm 288.9$. (Table V). A negative correlation $(r=$ - 0.227 ) was observed between duration of symptom with serum zinc level in this study (Figure 1).

Table-I

Distribution of the study of the subjects by age and sex

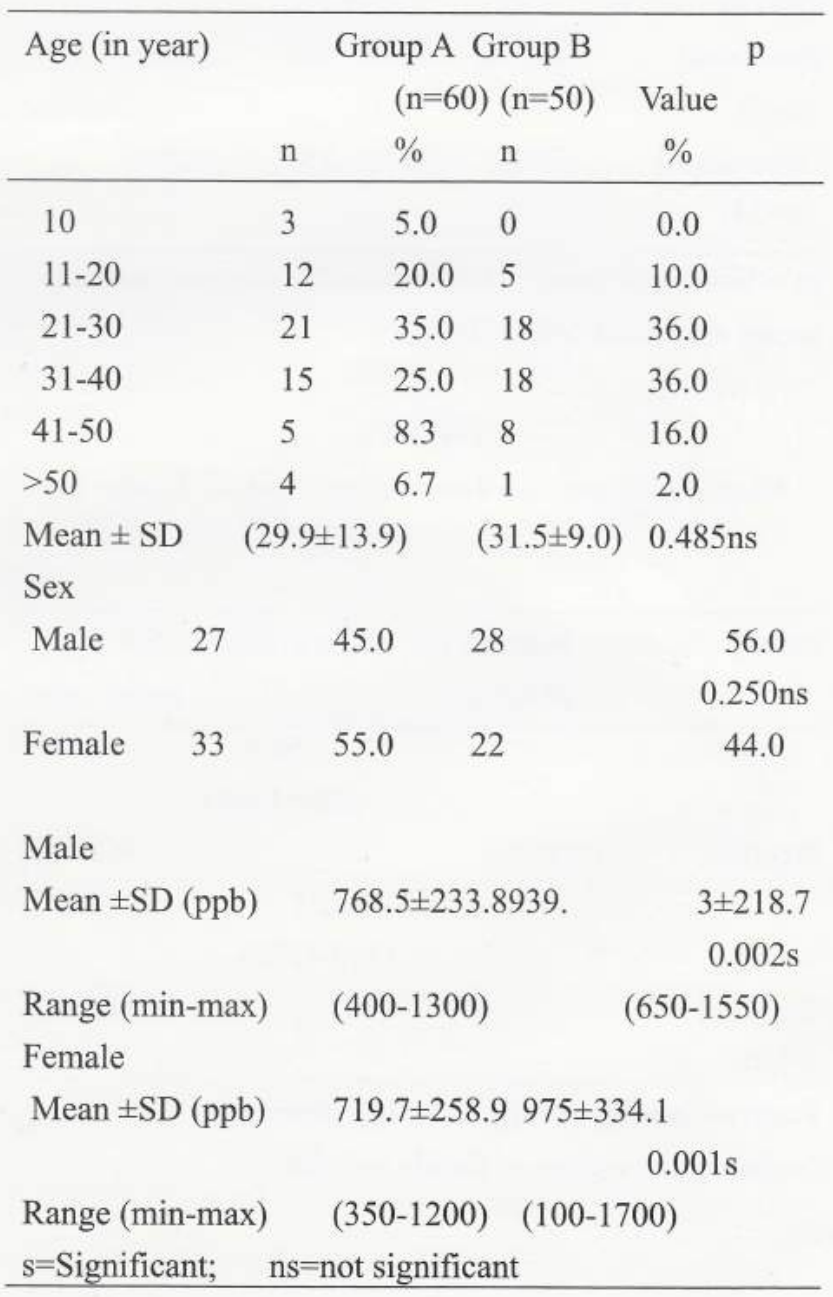


Table-II

Distribution of the subjects by serum zinc level $(n=110)$

\begin{tabular}{llllll}
\hline $\begin{array}{l}\text { Serum zinc } \\
\text { level }(\mathrm{ppb})\end{array}$ & \multicolumn{2}{l}{$\begin{array}{l}\text { Group A } \\
(\mathrm{n}=60)(\mathrm{n}=50)\end{array}$} & & Group B & $\begin{array}{c}\mathrm{p} \\
\text { Value }\end{array}$ \\
& $\mathrm{n}$ & $\%$ & $\mathrm{n}$ & $\%$ & \\
\hline Low $(<700 \mathrm{ppb})$ & 28 & 46.7 & 3 & 6.0 & $0.001 \mathrm{~s}$ \\
$\begin{array}{l}\text { Normal }(700- \\
1200 \mathrm{ppb})\end{array}$ & 31 & 51.7 & 41 & 82.0 & $0.001 \mathrm{~s}$ \\
High $(>1200 \mathrm{ppb}) 1$ & 1.7 & 6 & 12.0 & $0.027 \mathrm{~s}$ \\
Mean $\pm \mathrm{SD}$ & 741.7 & \pm 247.0 & 955.0 & \pm 273 & $0.001 \mathrm{~s}$ \\
\hline
\end{tabular}

$\mathrm{s}=$ Significant; $\quad \mathrm{ns}=$ not significant;

\section{Table-III}

Mean Zinc level according to different clinical types of vitiligo in group $A$.

\begin{tabular}{|c|c|c|c|c|c|}
\hline $\begin{array}{l}\text { Clinical types } \\
\text { of vitiligo }\end{array}$ & Mean & $\begin{array}{l} \pm \mathrm{SD} \\
(\mathrm{ppb})\end{array}$ & Min & $-\max$ & $\begin{array}{l}\mathrm{p} \\
\text { value }\end{array}$ \\
\hline $\begin{array}{l}\text { Localized/Focal } \\
(\mathrm{n}=19)\end{array}$ & 755.3 & \pm 288.6 & 400 & -1300 & \\
\hline $\begin{array}{l}\text { Acrofacial } \\
(\mathrm{n}=7)\end{array}$ & 821.4 & \pm 259.6 & 400 & -1100 & $\mathrm{c}_{0.632 \mathrm{~ns}}$ \\
\hline $\begin{array}{l}\text { Generalized } \\
(\mathrm{n}=34)\end{array}$ & 771.6 & \pm 222.2 & 350 & -1200 & \\
\hline
\end{tabular}

ns $=$ Not significant, $\quad$ *Internationally accepted normal serum zinc level (700-1200 ppb).

\section{Table-IV}

Mean serum zinc level according to family history in group $A(n=60)$

\begin{tabular}{lccr}
\hline Family History & $\begin{array}{l}\text { Number of } \\
\text { patients }\end{array}$ & Mean(range) $\begin{array}{l} \pm \text { SD } \\
(\mathrm{ppb}) \text { value }\end{array}$ \\
\hline & 756.9 & \pm 242.7 \\
& $(400-1300)$ &
\end{tabular}

Positive $\quad 51(85 \%)$

$0.299 \mathrm{~ns}$

$(350-1150)$

Negative

$09(15 \%)$
Table-V

Mean Zinc level according to duration of vitiligo.

Duration Number of Mean(range) $\quad \pm$ SD $\quad p$ of vitiligo patients (ppb) value ( (years)

\begin{tabular}{llll}
$<1$ & $11(18.3 \%)$ & $734.6(500-1300)$ & \pm 243.6 \\
$1-10$ & $39(65 \%)$ & $723.6(400-1200)$ & \pm 238.0 \\
& & & $0.523 \mathrm{~ns}$ \\
$11-20$ & $10(16.7 \%)$ & $780.0(350-1200)$ & \pm 288.9 \\
\hline
\end{tabular}
$\mathrm{ns}=$ Not significant.

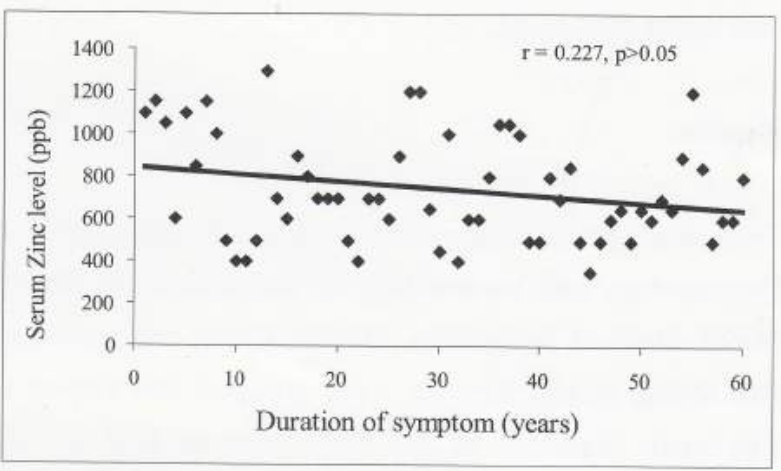

Fig I: Scatter diagram showing the negative correlation $(r=0.227 ; p>0.05)$ between duration of symptom with serum zinc level.

\section{Discussion :}

In this study the mean age was almost similar in both groups. Shameer et al. shown the mean age 33.8 years in vitiligo patients and 29.2 years in control, which is consistent with the current study.10 Shameer et al. found male female ratio was $4.5: 1 .{ }^{10}$ Male female ratio observed by Arora et al. was 2:1. ${ }^{11}$ These do not correspond with the current study where male female ratio was almost $0.8: 1$ in vitiligo patients. This may be due to the religious and social patterns of our country for which women may less frequently get chances to come to the physicians. Our study findings was similar with Shameer et al. regarding clinical type of vitiligo observed in their study. Shameer et al. reported that vitiligo vulgaris $(85.0 \%)$ was the commonest morphological pattern followed by mucosa vitiligo (10.0\%), segmental vitiligo (3.3\%) and acrofacial vitiligo (1.6\%). 10

In the present study, most of vitiligo patients had a positive family history, similar with Shameer et al. ${ }^{10}$ They 
They found $33.0 \%$ of the patients with positive family history. However, Shameer et al. found low levels of serum zinc in the majority of the patients with duration of disease ranging from 2 to 5 years, which corresponds with the current study. ${ }^{10}$ The mean duration of disease was $5.4 \pm 0.66$ years in this study. Shameer et al. found the mean duration of the disease was 2 years, which is a little lesser than the present study. ${ }^{10}$ This may be due to patients of our country usually come to health service centre in late stage of their disease.

A case control study by Shameer et al. showed low zinc level in $13(21.6 \%)$ out of the 60 patients. Only one patient showed an elevated level of zinc for the age and sex. The serum zinc levels in the control group were within the normal range. ${ }^{10}$ This corresponds with the current study. In this study serum zinc level was significantly lower in group-A than group-B. Serum zinc levels were studied by Arora et al in 75 patients of different cutaneous disorders and 24 healthy controls. ${ }^{13}$ No significant correlation was found in other cutaneous disorders studied.

Molokhia \& Portnoy found mean serum zinc level 9.1 $\mu \mathrm{g} / \mathrm{g}$ and $10.4 \mu \mathrm{g} / \mathrm{g}$ in vitiligo patients and control respectively. " Statistically mean serum zinc level of vitiligo patients was significantly lower than that of control. This also corresponds with the current study. Similar observations of significantly low serum zinc level in patients with vitiligo were made by Bruske \& Salfeld. ${ }^{12}$ A negative correlation was observed between duration of symptom with serum zinc level in this study which was not statistically significant. It indicates that serum zinc declines with increased duration of symptoms.

Arora et al. found no significant alteration in serum zinc level in vitiligo. This possibly supports the autoimmune theory of vitiligo. ${ }^{13}$ Conversely, Helmy et al. showed that serum zinc and copper levels were significantly higher in active vitiligo patients compared to controls. While serum zinc and copper levels insignificantly higher in active vitiligo versus stable disease and in stable patients versus controls. It appears that increased apoptosis of peripheral blood mononuclear cells in active vitiligo will lead to release of zinc and copper in serum (as zinc is present maximally intracellular), resulting in increasing their serum levels significantly in active vitiligo. ${ }^{14}$ Inamadar et al. reported appearance of vitiligo-like depigmented cutaneous lesions in two siblings with acrodermatitis entropathica who developed decreased serum zinc level due to discontinuation of zinc supplements. ${ }^{15}$

\section{Conclusion:}

This study has shown an important association between zinc level and vitiligo. Large-scale studies are needed to confirm these findings and multicenter study should be carried out to reveal the accurate pattern of zinc status in vitiligo.

\section{References:}

1. Koga M, Tango T. Clinical features and course of type A and type B vitiligo. BJD 2004; 118: 223-28.

2. Kovacs SO. Vitiligo. JAAD 2005; 38(5): 647-666.

3. Levai, M. A Study of Certain Contributory Factors in the Development of Vitiligo in South Indian Patients. Arch Dermatol 2008; 78: 364-370.

4. Schallreuter KU, Wood JM \& Berger J. Low catalase levels in the epidermis of patients with vitiligo. Investigative dermatology 2003; 97: $1081-5$.

5. Wood RJ. Assesment of marginal zinc deficiency in humans. Journal of Nutrition 2004;130(5): 1350.

6. Yildrim M, Baysal V, inaloz HS, Can MM. The role of oxidants and antioxidants in generalized vitiligo at tissue level. JEADV 2004; 18:683-686.

7. James WD, Berger TG, Elston DM. Vitiligo. Andrew's diseases of the skin: Clinical Dermatology.10th edi, Saunders- Elsevier publisher: Canada; 2006. 860-863.

8. Klotz LO, Kroncke KD, Buchezyk DP, Sies H. Role of copper,zinc,selenium and tellurium in cellular against oxidative and nitrosative stress. Journal of Nutrition 2003;133: 1448-1451.

10. Castanet J, Ortone JP. Pathophysiology of vitiligo. Clinical Dermatology, 2003; 15: 845-851.

11. Shameer P, Prasad PVS, Kaviarasan PK. Serum zinc level in vitiligo: case control study. IJDVL 2005;71(3): 206-207.

12. Molokhia MM \& Portnoy B. Neutron activation analysis of trace elements in skin VII.Copper and Zinc in Vitiligo. Moles and Seborrhoic Warts. BJD 2001; 88(4): 347-353 .

13. Bruski K, Salfeld K. Zinc and its status in dermatologic diseases - a statistical assessment. U S Nationtal library of Medicine 2003;11: 93-95.

14. Arora PN, Dhilon PS, Rajan SR, Sayal SK and Das AL. Serum zinc level in cutaneous disorders. MJAFI 2002;58(4): 304-6.

15. Helmy MI, Gayyar EL, Hawas S, Eissa AE. Role of oxidative stress in the pathogenesis of vitiligo. J Pan-Arab League Dermatologist. 2004;15: 97-105.

16. Inamadar $\mathrm{AC}$, Palit A. Acrodermatitis entropathica with depigmented skin lesions simulating vitiligo.Pediatr Dermatol. 2007;24: 668-9. 